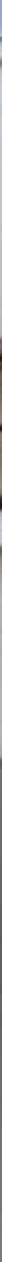

Vista exterior de la galería del colegio Lope de Vega. Foto: Juan Carlos Cazalla, IAPH 


\section{La Ciudad Jardín de Almería. La condición compleja del patrimonio urbano contemporáneo}

Plácido González Martínez, Marta Santofimia Albiñana, Centro de Documentación y Estudios, Instituto Andaluz del Patrimonio Histórico
La Ciudad Jardín de Almería (1940-1947), obra del arquitecto GuiIlermo Langle, surge en la posguerra como experimento residencial destinado a implantar, a las afueras de la ciudad, un nuevo modelo que significase las aspiraciones del Régimen, a la manera de manifiesto dedicado a la última capital andaluza en mantenerse fiel al gobierno de la República. Buscando un "nuevo comienzo" para dar solución al problema de la residencia marginal en la periferia urbana, la Ciudad Jardín se situó al sureste de la ciudad, aislada por el trazado del ferrocarril, constituyéndose como colonia de 245 viviendas organizadas en torno a un espacio central ajardinado que ponía en relación el programa de edificios públicos compuesto por la iglesia, el edificio de servicios municipales, el colegio y el mercado.

Teniendo en cuenta estas aspiraciones de "nuevo comienzo" con las que fue impulsada, nos aproximaremos a la Ciudad Jardín de Almería reconociéndole un carácter complejo heredado de distintas teorias urbanísticas y arquitectónicas surgidas a finales del siglo XIX y comienzos del XX, de las que habremos de seleccionar una serie de valores que constituyen su aportación singular.

En primer lugar, podríamos decir que el proyecto de Langle se nos presenta como un "caballo de Troya" encargado de introducir en el contexto del sur peninsular una nueva forma de habitar procedente de la modernidad industrial europea; la ciudad jardin propuesta por Ebenezer Howard en 1898, un modelo que tuvo que adaptar sus caracteristicas espaciales, económicas y sociales a las singularidades culturales del lugar. Como respuesta a la cuestión dolorosa de la vivienda obrera en la ciudad industrial occidental, las teorias de la ciudad jardin pasaron a la historia como el primer modelo de organización urbana provisto de conciencia global, que pretendía universalizar al grueso de la sociedad moderna las ventajas de la vida en contacto con la naturaleza que hasta entonces sólo habian conocido los sectores más aventajados de la burguesía.

Sin embargo, y como demostraron las propias realizaciones de Howard en los casos pioneros de las ciudades de Letchworth (1903) y Welwyn (1919), la ambición del alcance de las ideas de la ciudad jardin fue en detrimento de la integridad de su concepto y a favor del abandono de ciertas metas que se había marcado originariamente. Así ocurrió también en España, donde a pesar de la vinculación de la ciudad jardin a los programas de casas baratas, los esfuerzos que impulsaron al estudio de las relaciones entre espacios públicos y privados, del control de la densidad edificatoria, de la cualificación ambiental a través de la vegetación y de la racionalización de la vivienda fueron destinados a un segmento privilegiado de la burguesía, que aprovechó el paradigma del aislamiento para constituir archipiélagos aislados del resto de la ciudad.

Al mismo tiempo, y también desde sus orígenes, el propósito de autonomía productiva y social que pretendia conseguir Howard con la ciudad jardín a través de la presencia de la industria, la asociación con la agricultura y la separación respecto a la metrópolis, dio paso a un modelo sucedáneo, el del suburbio jardin, desarrollado en Inglaterra por Raymond Unwin tras su experiencia en Letchworth, en el que las intuiciones ambientales de la relación entre arquitectura y naturaleza terminaron prevaleciendo sobre los fundamentos sociales y económicos originales.

El modelo de la ciudad jardín se planteaba a nivel teórico como paradigma urbano de la individualidad, renunciando inicialmente a definir modelos residenciales o estilos arquitectónicos. Por el contrario, en su puesta en práctica, y como muestra la obra de Langle, hubo de materializarse adaptándose a un proceso de homogeneización propio de los nuevos ritmos de producción de la vivienda, convertida en la principal cuestión a resolver en la arquitectura del siglo XX. Siguiendo los ejemplos pioneros alemanes de las grandes Siedlungen promovidas durante la República de Weimar, así como en los ejemplos españoles de las colonias de Parque Residencia (1931-1934) y EI Viso (1933-1936), construidas durante la Segunda República en Madrid, la arquitectura de la ciudad jardín de Almería se sometió a un proceso de depuración. Estas tres cuestiones: ciudad jardin, suburbio jardin, y colonias, hubieron de ponerse en juego para la Ciudad Jardín de Almería en un contexto de cambio radical como era la España de 1940: el ses- 
go politico de los promotores de las ciudades colonias, impulsadas desde el socialismo durante la República, pasó a situarse en el extremo opuesto. La mentalidad conservadora y sus paradigmas de la unidad ideológica, la independencia cultural, la recuperación de las aspiraciones imperialistas, la autarquía económica, etc., constituyeron el filtro por el cual debieron pasar y reformularse.

Teniendo en cuenta todos estos condicionantes previos en la génesis y realización del proyecto de Langle, la Ciudad Jardin que conocemos por la documentación fotográfica de la época presenta una imagen utópica de espacios ajardinados en contacto con una arquitectura preparada para disolverse en una naturaleza aún en sus brotes, de aislamiento físico de la colonia respecto a la ciudad, de homogeneidad tipológica, constructiva y cromática de la arquitectura, de especial cuidado en las transiciones entre los espacios públicos y los privados..., escena que con el paso del tiempo fue sucumbiendo a la dinámica del crecimiento urbano que la engulló y a las nuevas aspiraciones de los propietarios que la transformaron.

Ante esta situación de cambio acelerado, aparecen inevitablemente cuestiones de trascendencia patrimonial relativas a su esencia: a la hora de enfrentarnos a una muestra de patrimonio urbano contemporáneo en la que confluye una selección de valores tan complejos, ¿es posible considerar cada uno de estos valores por separado? ¿Podemos reclamar a la Ciudad Jardín de Almería fideli- dad a las aportaciones de Howard, Unwin y los defensores del modelo de las Siedlungen? ¿Podríamos, en tal caso, considerar justificadas las adaptaciones realizadas por los sucesivos propietarios sobre las viviendas de Langle, en coherencia con el paradigma de la individualidad de las teorias de Howard, a pesar de que nunca estuvieron presentes en el proyecto?

En este sentido, podriamos entenderlo como un hojaldre de valores, en el que las texturas se superponen, y es precisamente en los matices que marcan el tránsito de unas capas a otras donde se revela la riqueza patrimonial del conjunto de la Ciudad Jardín hoy día. Cabe considerar entonces a la Ciudad Jardín de Almería en términos de autonomía urbana en la línea del suburbio jardín inglés del que Hempstead (1909), obra de Raymond Unwin, sirve de claro ejemplo; o resaltando la preocupación por los aspectos ambientales heredados de las teorias de Howard; o bien, señalando la apuesta por la unidad estética, tipológica y formal como conceptos heredados de las Siedlungen, donde la homogenización jugaba un papel fundamental. Formando parte de esta lectura integral y compleja, habremos de referirnos a estas tres cuestiones, insistiendo en su aportación para la configuración de una identidad para la ocupación urbana de la periferia almeriense.

Comenzaremos por el valor de la autonomía urbana, que es el punto de partida de las teorias de Howard, si bien para la Ciudad Jardin de Almería se manifiesta desprovisto del sentido económi-

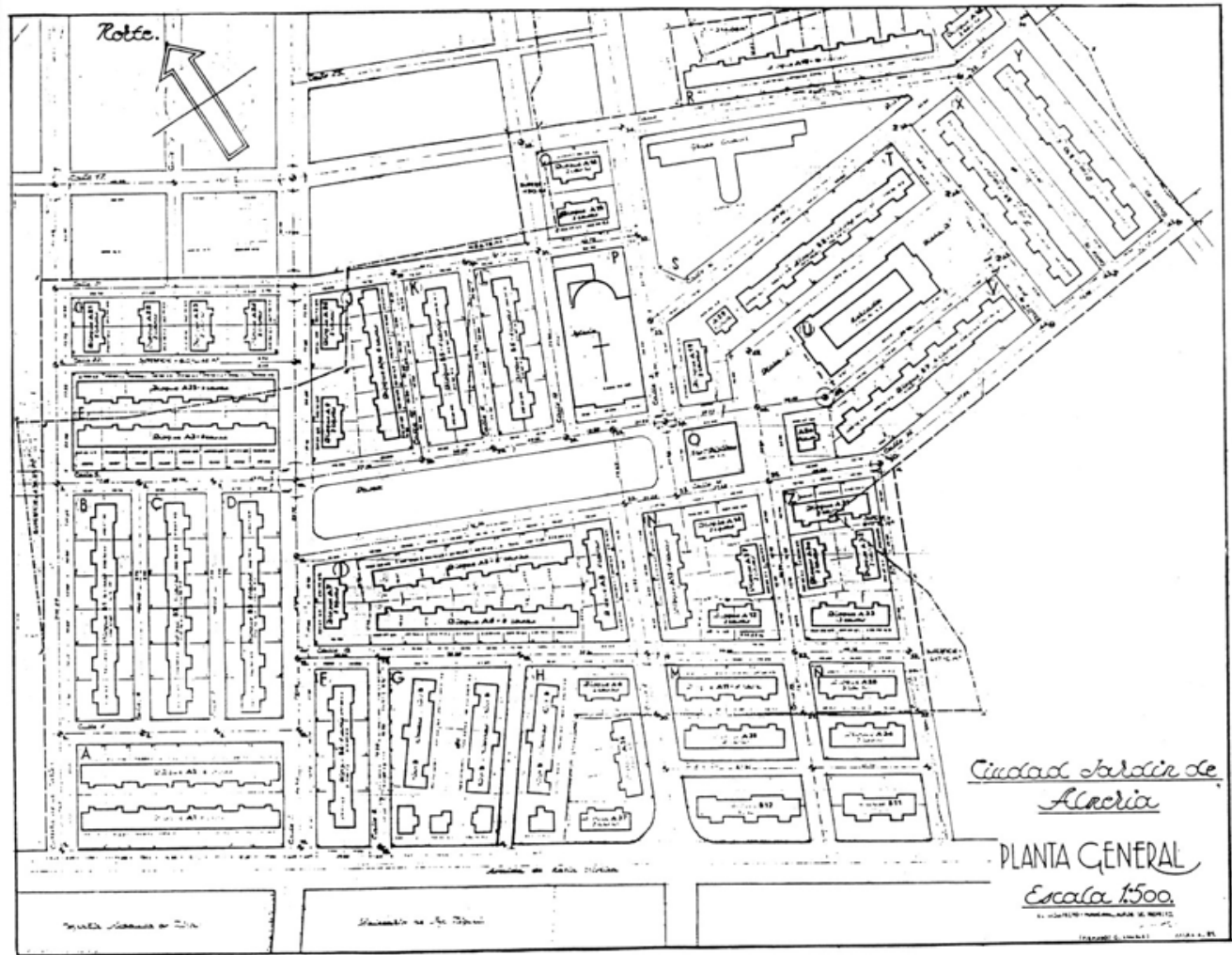


co, para insistir exclusivamente en la creación de un modelo espacial aislado, próximo a la pequeña ciudad que Heinrich Tessenow definió en 1919 para regenerar la vida urbana en la Alemania de entreguerras. La importancia de este referente conservador, en el que la recuperación de la vida comunitaria se confiaba a las certezas de la ciudad preindustrial, se evidencia en la relevancia que toma la iglesia para el proyecto de Langle, entendida como punto de referencia del conjunto respecto a la capital. Desde el acceso privilegiado que se consigue desde la calle de Castilla, la Iglesia de San Antonio de Padua muestra toda su carga simbólica hacia el espacio público central de la ordenación, que no de manera casual recibió el nombre de la Plaza de España.

Este espacio, de planta rectangular alargada, se ofrece como lugar de encuentro comunitario, y muestra al edificio de servicios públicos como remate en su lado este, sirviendo de nuevo hito de una manera secundaria respecto a la iglesia. Se establece, por tanto, una jerarquia clara en las dotaciones del barrio: la iglesia y el edificio de servicios públicos ofrecen la cara más representativa de la Ciudad Jardín, mientras que los otros dos equipamientos, como son el magnífico edificio racionalista del colegio Lope de Vega y el mercado, se integran en el tejido residencial, a una escala más modesta y doméstica.

La creación de ciertas escenas identitarias: con los valores de estabilidad que proporcionaba la iglesia; los de educación que transmitía el colegio; de intercambio económico a pequeña escala que incorporaba el mercado y la existencia de un poder político, como ofrecia el edificio administrativo, resultaba prioritaria. Por esta razón, se debería considerar que, por encima de las necesarias adaptaciones que se imponen a estos edificios, como ha sido el caso de la escuela y sus sucesivas ampliaciones, es necesario mantener la integridad de otras presencias y su vinculación originaria al resto de la Ciudad Jardin; hecho que no ha ocurrido en el mercado y el edificio público, hoy día desaparecidos y sustituidos por piezas y usos que no han participado de los valores del conjunto.

En segundo lugar, podríamos identificar valores ambientales en la escala más menuda del proyecto, en la relación que se pretende entre calle y casa, que ofrece la oportunidad de experimentar consiguiendo interesantísimos resultados. El estudio de los espacios ajardinados de la Ciudad Jardín de Almería saca a relucir la trascendencia de los elementos de cierre de las parcelas: muretes, pilastras, celosías de hormigón armado y vegetación, que gracias a su transparencia y su baja altura permiten una relación fluida entre el espacio público y el espacio privado. De igual forma, la importancia del control de las secciones del viario, del cuidado en la elección de especies vegetales y su disposición en los espacios abiertos, ofrece claves para entender la aportación del proyecto de Langle a nivel paisajístico.

Esto se hace extensivo a la cuidada volumetria de los distintos tipos de viviendas desde el proyecto, que procuraban la ruptura de la calle corredor, la reducción de altura en las esquinas merced a la creación de porches abiertos a los jardines, así como terrazas

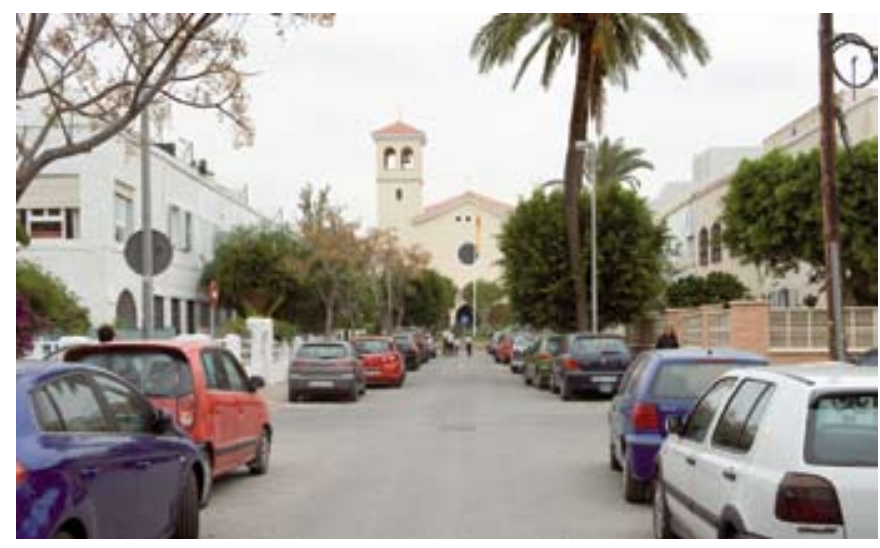

Vista de la Iglesia San Antonio de Padua desde la calle Castilla. Foto: Juan Carlos Cazalla, IAPH

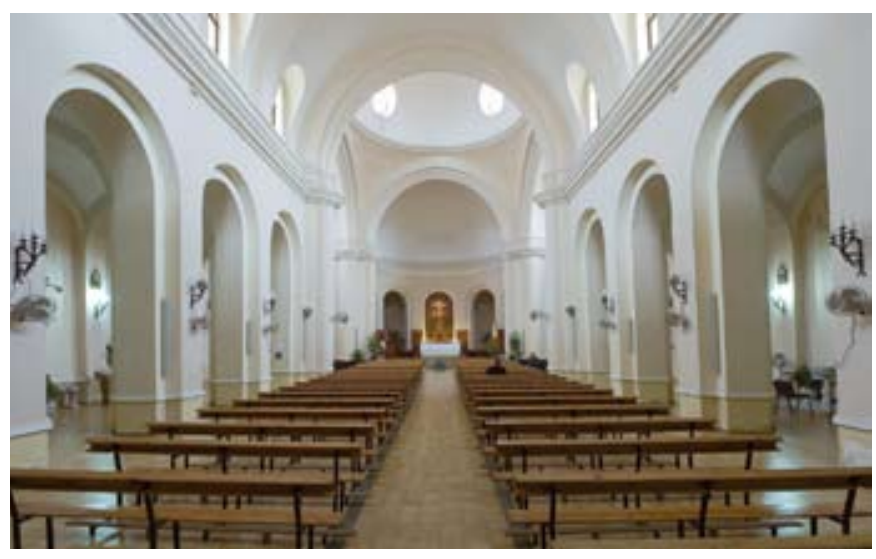

Arcos de la nave principal de la Iglesia de San Antonio de Padua. Foto: Juan Carlos Cazalla, IAPH

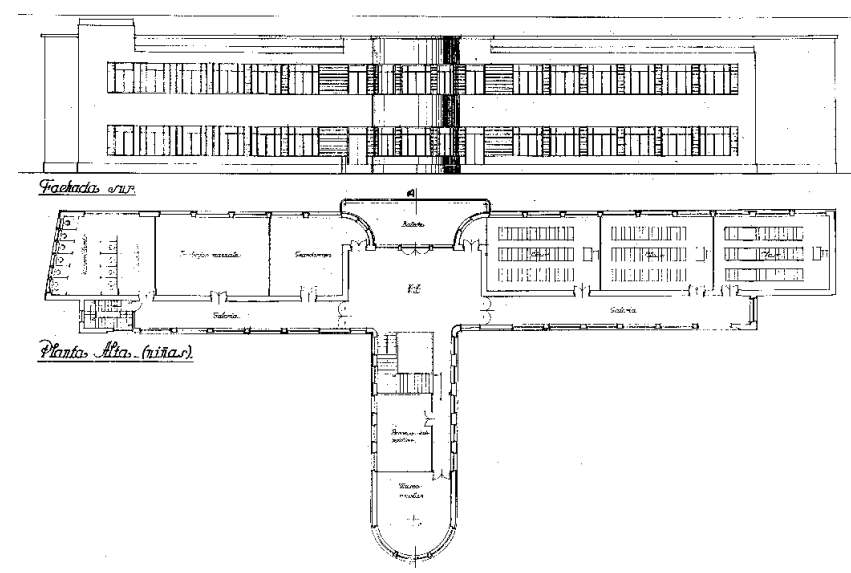

Planta alta y fachada sur del colegio Lope de Vega. Fuente: Archivo Municipal de Almería

que esponjaban la relación entre el espacio construido y el espacio libre. Gracias a los esfuerzos compositivos por conseguir variedad en los tipos de vivienda, y organizar de manera casual los volúmenes edificados, el efecto final fue indudablemente pintoresco, traduciendo para la modernidad las búsquedas que la arquitectura suburbana del siglo XIX habia hecho desde lo vernacular, entendido como lo azaroso y lo desordenado.

Lamentablemente, encontramos que las operaciones puestas en juego por Langle para conseguir la calidad ambiental han tenido una evolución completamente azarosa: Ios tipos han sido alterados hasta hacerse en algunos casos irreconocibles, incorporándo- 


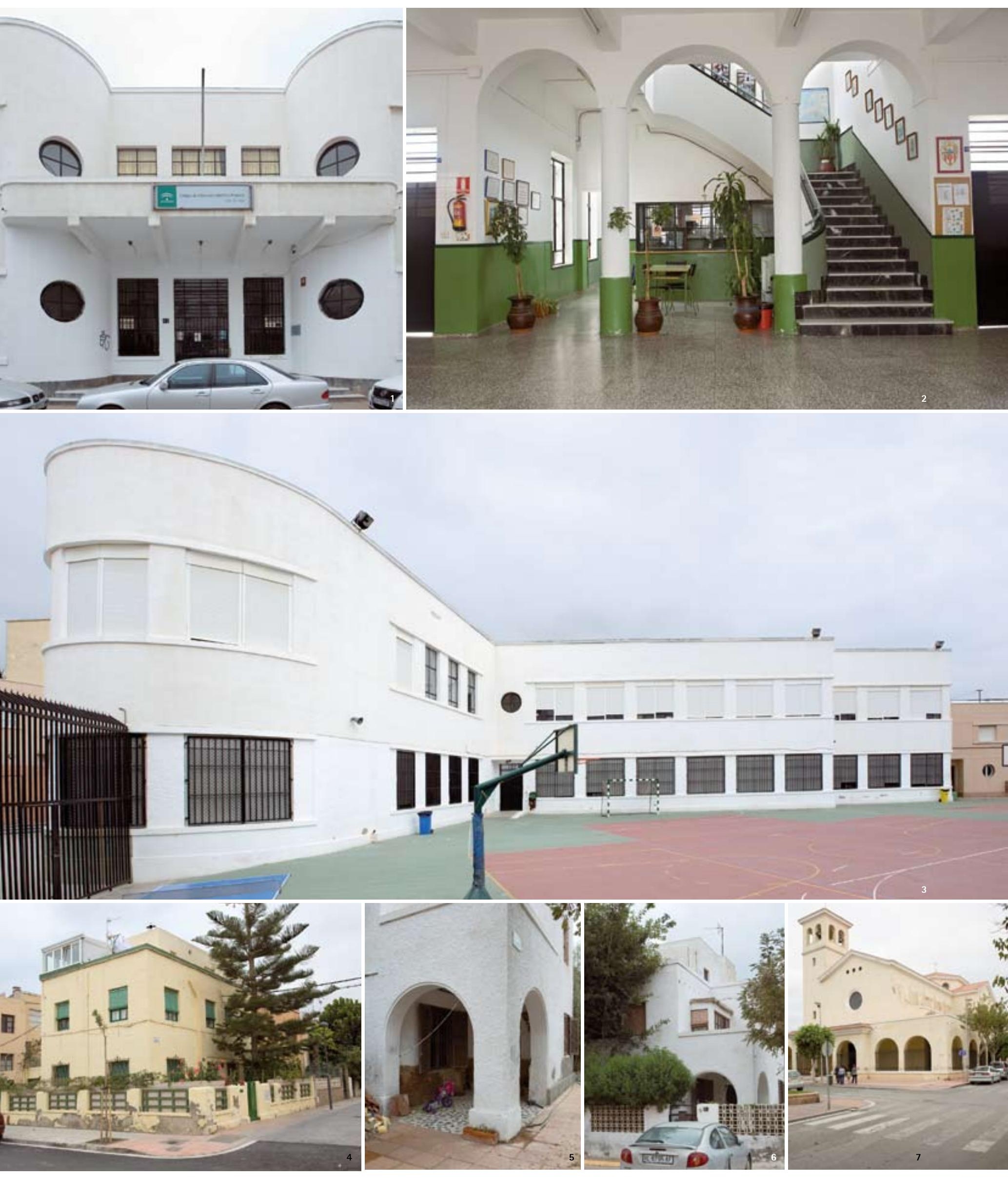


se al espacio habitable de las viviendas los elementos singulares de las azoteas y los porches, derivando en una imagen hinchada y compacta de lo que fue en otro tiempo una arquitectura modesta y porosa. De igual manera ha ocurrido con los elementos que estaban destinados a reforzar el sentido identitario como es el caso de los cierres de parcelas, que han sido en su mayor parte sustituidos y elevados, perdiendo transparencia y evidenciando asi la tendencia a la fortificación del espacio privado en la ciudad contemporánea.

En tercer lugar, nos encontramos con la apuesta que se realizó desde las primeras Siedlungen alemanas por la homogeneización y el mantenimiento de los elementos que, a nivel compositivo, dan unidad al proyecto. Estas variaciones controladas de la arquitectura de la ciudad jardín se correspondian con intentos por homogeneizar el conjunto, que se plasmaban en diversas estrategias de proyecto. Una de ellas era la apuesta por tipificar cuatro modelos de viviendas, que se asociaban en grupos colectivos y unifamiliares. Al mismo tiempo, se trataba de incorporar elementos que diesen unidad al conjunto, como los cierres de parcela anteriormente mencionados, la agrupación horizontal de huecos en la composición de las fachadas y la reivindicación de un elemento característico de la racionalidad mediterránea, tal como la entendian los arquitectos italianos del momento, como es el arco de medio punto, y que sirve para enlazar episodios tan diversos de la ciudad jardín como las viviendas en sus accesos, la iglesia en su porche, y la escuela en su vestíbulo.

Las nuevas necesidades domésticas de los propietarios, acompañadas por el desarrollo económico reciente, han hecho el resto: Ios arcos, que constituian elementos de transición entre los porches y los espacios abiertos, han sido cegados en su mayoria, mientras que en los últimos años hemos asistido a la sustitución de algunos de los tipos de vivienda originales de Langle por nuevos proyectos que se han implantado en el contexto de manera generalmente ajena y autista.

Como conclusión, la Ciudad Jardín de Almeria sigue ofreciendo hoy dia una imagen de relativa integridad, gracias a la generosidad con la que los pioneros de la Ciudad Jardín pusieron las bases de una nueva forma urbana para el futuro. Aun asi, hemos de señalar que las demoliciones y adiciones, cambios de uso y sustituciones, comprometen seriamente la pervivencia de esa mismas ventajas de las que ha disfrutado hasta ahora. Sólo desde la consideración a la integridad material y espacial del conjunto, asi como al mantenimiento del equilibrio social que provenía de la mezcla de usos, podremos seguir hablando de un ejemplo vivo de patrimonio urbano contemporáneo.

\section{En la web}

\section{CONJUNTO MONUMENTAL DE LA ALCAZABA DE ALMERÍA \\ www.juntadeandalucia.es/cultura/ museos/CMAAL}

Portal de Museos y Conjuntos Arqueológicos y Monumentales de Andalucía de la Consejeria de Cultura de Andalucia.

En esta web podrá encontrar información sobre su acceso, oferta de servicios, investigaciones realizadas, ex posiciones, actividades, publicaciones entre otros recursos de interés sobre este Conjunto Monumental.

\section{ASOCIACIÓN CULTURAL TRADICIÓN Y VANGUARDIA DE ALMERÍA.} GUILLERMO LANGLE

www.tradicionyvanguardia.com

langle/guillermolangle.htm

El sitio web de esta asociación dedica todo un monográfico al arquitecto GuiIlermo Langle. Información exhaustiva sobre su vida y obra asi como su bibliografía más destacada.
PORTALMERIAA.COM

www.portalmeria.com

En la sección Conoce Almería de este Portal Web podrá encontrar información sobre los municipios que conforman el valle de Andarax y el campo de Tabernas. Cada municipio ofrece datos sobre su localización, historia, lugares de interés, fiestas y tradiciones, direcciones y enlaces de interés.

\section{MUSEO DE ALMERÍA \\ www.juntadeandalucia.es/cultura/ museos/MAL}

Portal de Museos y Conjuntos Arqueológicos y Monumentales de Andalucia de la Consejeria de Cultura de Andalucía.

Información general, historia del museo, colecciones, publicaciones, actividades y exposiciones son algunos de los recursos a los cuales podrá acceder en este espacio.

\section{ASOCIACIÓN DE AMIGOS DEL FERROCARRIL DE ALMERÍA \\ www.asafal.es}

Asociación dedicada a fomentar y dar a conocer todo lo que conforma el mundo del ferrocarril.

La asociación hace uso de la herramienta Google Earth para representar antiguas líneas de ferrocarril, marcar estaciones, cargadores, minas, etc.

Este sitio web también ofrece un amplio elenco de imágenes así como enlaces relacionados con el mundo del ferrocarril en el ámbito nacional e internacional.

\section{RUTA PAISAJES DE CINE \\ www.paisajesdecine.com}

Web dedicada a mostrar la ruta Paisajes de cine elaborada por la Diputación de Almería.

Esta ruta se desarrolla en el desierto de Tabernas y Sierra Alhamilla y recorre los escenarios más emblemáticos en los que se rodaron dos famosas películas: La muerte tenía un precio e Indiana Jones y la última cruzada.

\section{PLATAFORMA SOLAR DE ALMERÍA} www.psa.es

Sitio web de la Plataforma Solar de Almería ubicada en el desierto de Tabernas. El mayor centro de investigación solar de Europa.

Este proyecto del Ministerio de Ciencia e Innovación pertenece a la Red de Espacios de Divulgación Científica y Técnica de Andalucía.

\section{PATRIMONIO INDUSTRIAL EN ANDALUCIAA ORIENTAL}

www.patrimonioandaluz.com

Esta web pretende crear un catálogo on-line de los principales elementos de patrimonio industrial de las provincias de Almeria, Granada y Jaén, para contribuir a la divulgación de sus valores arquitectónicos, culturales y etnográficos. De forma novedosa, se incluye una sección que recoge la localización exacta de los elementos en forma de POIS (Puntos de Interés en formato GPS). 